\title{
PENGARUH KUALITAS PRODUK, PERSEPSI HARGA, DAN KUALITAS LAYANAN TERHADAP KEPUASAN KONSUMEN
}

\author{
Jonathan Herdioko, dan Valentcio Luwiska W \\ Fakultas Bisnis, Universitas Kristen Duta Wacana, \\ Daerah Istimewa Yogyakarta \\ Email korespondensi: jonherdioko@gmail.com
}

\begin{abstract}
ABSTRAK
Penelitian ini bertujuan untuk mengetahui pengaruh kualitas produk, persepsi harga, dan kualitas pelayanan terhadap kepuasan konsumen pada Toko Tekstil Mac Mohan, Solo. Populasi dalam penelitian ini adalah penduduk Kota Solo. Teknik penyampelan menggunakan nonprobability sampling dengan pemilihan 100 responden yang pernah membeli produk di Mac Mohan Solo. Teknik pengumpulan data dilakukan dengan menyebarkan kuesioner yang telah diuji validitas dan reliabilitasnya. Metode analisis regresi linier berganda digunakan dengan uji R2, uji F, dan uji t. Hasil pengujian menghasilkan nilai sig uji $\mathrm{F}$ sebesar $=0,00$, artinya secara simultan variabel kualitas produk, persepsi harga, dan kualitas pelayanan berpengaruh signifikan terhadap kepuasan konsumen. Hasil uji t menunjukkan bahwa kualitas produk, persepsi harga, dan kualitas layanan secara parsial berpengaruh signifikan terhadap kepuasan pelanggan.
\end{abstract}

Kata Kunci: kualitas produk, persepsi harga, kualitas layanan, kepuasan pelanggan

\begin{abstract}
This study aims to determine the effect of product quality, price perception, and service quality toward customer satisfaction at Toko Tekstil Mac Mohan, Solo. The population in this study are the residents of Solo. Non-probability sampling method is adopted with a selection of 100 respondents who have bought products at Mac Mohan Solo. Data collection techniques were carried out by distributing questionnaires that had been tested for validity and reliability. The multiple linear regression analysis method is used with $\mathrm{R} 2$ test, $\mathrm{F}$ test, and $\mathrm{t}$ test. The test results produce a sig value of $F$ test of $=0.00$, meaning that simultaneously, the variable product quality, price perception, and service quality have a significant effect on customer satisfaction. The $t$ test shows that product quality partially, price perception, and service quality partially have a significant effect on customer satisfaction.
\end{abstract}

Keywords: product quality, price perception, service quality, customer satisfaction

\section{PENDAHULUAN}

Era modern ini banyak sekali masyarakat yang ingin tampil menawan dan salah satu hal yang dapat merealisasikannya adalah busana. Busana atau yang lebih akrab dengan sebutan pakaian ini menjadi salah satu kebutuhan manusia yang tidak dapat dihindari. Namun seiring berkembangnya waktu, busana telah menjadi suatu kebutuhan sekaligus keinginan bagi masyarakat. Jika membahas soal berbusana tentu saja tidak akan ada habisnya. Bagaimana tidak, kehidupan dari waktu ke waktu secara tidak sadar membawa masyarakat memunculkan tren-tren baru dalam berbusana. Bahkan jika berbicara mengenai habis atau hilangnya tren berbusana sangatlah tidak mungkin karena 
tren berbusana itu seperti roda berputar yang akan terus terulang, seperti busana dengan motif animal print yang menjadi tren pada era 90an ini. Di samping itu, pembuatan busana tentu tidak lepas dari industri tekstil. Sektor industri yang bergerak di bidang tekstil ini merupakan salah satu sektor yang mendorong pendapatan Indonesia. Sektor industri ini menopang dan berpotensi untuk menumbuhkan perkonomian negara Indonesia dimana sektor industri siap dalam menghadapi persaingan Asean Economic
Community (AEC). Kemenperin RI mengatakan ada tiga sektor utama yang menopang pertumbuhan industri pengolahan non-migas pada kuartal kedua tahun 2019. Industri tersebut antara lain industri kertas, industri makanan dan minuman, serta industri tekstil dan pakaian yang tumbuh mencapai 20,71\% (Kemenperin.go.id, 2019). Oleh karena itu, bisnis tekstil menjadi salah satu bisnis dengan peluang yang besar di kota Solo hingga saat ini.

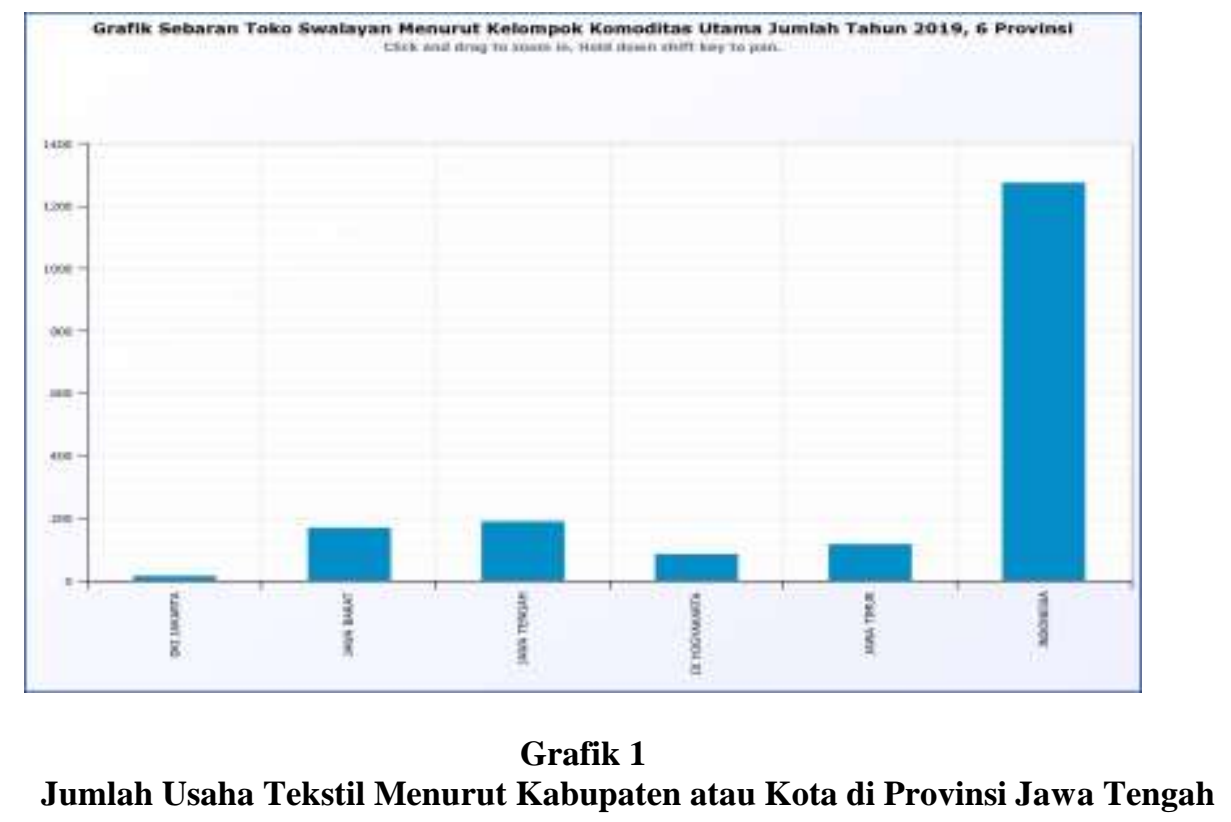

Sumber: https://www.bps.go.id

Berdasarkan tabel di atas, provinsi Jawa Tengah memiliki sebaran usaha tekstil terbanyak pada tahun 2019 dibandingkan provinsi yang ada di Indonesia dengan jumlah usaha keseluruhan 193 usaha. Melihat hal ini persaingan antar usaha tekstil sudah terlihat seperti berada diarea perang dimana usahausaha tersebut akan bersaing dengan apapun yang dimilikinya untuk bertahan dan menjadi yang terdepan. Bagaimana sebuah usaha tekstil dapat terus berjalan dan berkembang di tengah persaingan yang sangat ketat ini? Philip Kotler dalam bukunya "The Journal of Business Strategy" mengatakan "Tahun 1990-an tidak hanya tentang siapa yang dapat memproduksi barang dengan lebih murah, berbeda atau lebih baik, tetapi dekade ini juga akan mendukung mereka yang dapat memproduksinya lebih cepat". Kalimat ini sangat cocok untuk para pengusaha yang ingin menjadi "terdepan" dalam persaingan bisnis, tidak hanya untuk bisnis di bidang tekstil saja untuk segala bentuk usaha kecepatan dan ketepatan dalam pelayanan merupakan tuntutan konsumen di era modern dan digitalisasi saat ini, meningkatnya globalisasi disegala jenis bidang dan dunia luar yang semakin transparansi, maka tidak ada lagi batasan konsumen, waktu, dan jarak. Menurut Philip Kotler (2001), kepuasan konsumen merupakan tingkat perasaan setelah membandingkan hasil yang mereka peroleh dibandingkan dengan besarnya harapan sebelum ia peroleh barang tersebut. Bila kinerja melebihi harapan mereka akan merasa puas dan sebaliknya bila kinerja tidak 
sesuai harapan maka akan kecewa. Sedangkan menurut Mowen (2002), kepuasan konsumen adalah sikap keseluruhan terhadap suatu produk atau jasa setelah diperoleh dan pemakaiannya.

Di awal tahun 2020, pendapatan pada semua sektor perekonomian kian menurun karena adanya wabah Covid-19 yang menyebar di seluruh dunia hingga mengguncang keuangan masyarakat terutama di Indonesia. Dengan adanya wabah ini tentu saja masyarakat menginginkan segala sesuatu dengan harga yang terjangkau. Di kota Solo terdapat beberapa toko tekstil yang masih bertahan dan bahkan berkembang hingga saat ini. Salah satu yang telah ada sejak dulu adalah toko tekstil Mac Mohan. Sebagai toko tekstil yang telah dikenal oleh masyarakat, Mac Mohan telah berdiri sejak tahun 1965 di Coyudan, kota Solo dan telah berpindah ke Jl. Gatot Subroto No. 42, Kemlayan, kota Surakarta hingga saat ini. Didirikan oleh Mr. Tarachand Alimchand Chainani, Mac Mohan telah memperluas jangkauannya dengan mendirikan cabang di Benteng Trade Center (BTC), Kartasura, dan Delanggu yang masih bertempat di kota Solo. Mac Mohan juga membuka cabang di kota lain, diantaranya Wonogiri, Ungaran, Salatiga, dan Madiun. Selain itu Mac Mohan juga mulai mempromosikan usahanya melalui marketplace seperti Shopee, Tokopedia, Instagram, dan aplikasi WhatsApp. Mac Mohan menjual beraneka ragam jenis kain dan gordyn, mulai dari kualitas standar hingga terbaik. Mac Mohan juga melayani pembelian ecer, grosir, partai, dropshiper, juga pembelian online.

Menurut penulis, toko tekstil Mac Mohan sangat menarik untuk diteliti. Memiliki harga kain yang relatif murah dan banyak pilihan jenis dan warna, juga menyuguhkan lokasi yang strategis. Demi mempertahankan kepuasan konsumen, Mac Mohan sangat memperhatikan kualitas kain dan pelayanannya. Saat ini, Mac Mohan menjadi salah satu toko tekstil yang digemari masyarakat sekaligus menjadi salah satu icon pusat perbelanjaan tekstil terbesar di kota Solo. Sehingga, berdasarkan latar belakang di atas, penulis tertarik melakukan penelitian dengan judul Analisis Pengaruh Kualitas Produk, Persepsi Harga, dan Kualitas
Layanan Terhadap Kepuasan Konsumen di Toko Tekstil Mac Mohan, Solo.

\section{KAJIAN LITERATUR DAN PENGEMBANGAN HIPOTESIS}

\section{Pengaruh Kualitas Produk terhadap Kepuasan Konsumen}

Meningkatkan kualitas produk, persepi harga, dan meningkatkan kualitas layanan merupakan cara perusahaan dalam meningkatkan kepuasan konsumen. Hal ini dapat dilihat dengan melalui produk yang dinilai sudah terbukti baik dengan melihat riwayat dari produk tersebut yang tersebar di masyarakat yaitu kemampuan dan kesanggupan untuk membantu konsumen dan menyediakan produk sesuai ketentuan, harga yang dapat diterima dengan kualitas produk yang diberikan, dan perusahaan memberikan pelayanan terbaik sehingga konsumen juga merasa dihargai. Kualitas produk adalah kemampuan suatu produk dalam memberikan hasil atau kinerja yang sesuai bahkan melebihi dari apa yang diinginkan pelanggan Philip Kotler (2016).

$\mathrm{H}_{1}$ : Kualitas produk berpengaruh terhadap kepuasan konsumen.

\section{Pengaruh Persepsi Harga terhadap Kepuasan Konsumen}

Persepsi bagian dari proses penilaian individu terhadap lingkungan disekitarnya. Persepsi akan muncul dengan sendirinya sesuai dengan situasi dan kondisi dimana individu berada. Kebanyakan orang berpersepsi kepada barang, produk, atau merk saja, akan tetapi persepsi ini juga dapat timbul dari hubungan seseorang dengan lingkungannya. Persepsi tidak hanya berpengaruh pada barang dan merk saja akan tetapi kini harga dan keputusan pembelian seseorang juga dipengaruhi oleh persepsi konsumen. Harga tidak hanya sebuah angka akan tetapi harga dapat mengikat para calon konsumen menjadi konsumen, kemudian menjadikan konsumen tetap yang melakukan pembelian ulang di toko tersebut. Menurut Assauri (2014), harga merupakan unsur dalam bauran pemasaran yang dapat diterima dalam penjualan. 
$\mathrm{H}_{2}$ : Persepsi harga berpengaruh terhadap kepuasan konsumen

\section{Pengaruh Kualitas Layanan terhadap Kepuasan Konsumen}

Faktor yang mempengaruhi sebuah kepuasan yaitu layanan yang diharapkan dan layanan yang diterima. Jika layanan yang diterima memenuhi apa yang diharapkan maka jasa dapat dikatakan baik, akan tetapi sebaliknya layanan yang diterima lebih jelek dibandingkan layanan yang diharapkan, maka kualitas pelayanan dipersepsikan buruk. Supranto (2006) mengatakan kualitas pelayanan merupakan sebuah kata yang bagi penyedia jasa merupakan sesuatu yang harus dikerjakan dengan baik. Kualitas pelayanan sebagai ukuran seberapa bagus tingkat layanan yang diberikan mampu sesuai dengan ekspektasi pelanggan Lewis (1983) yang dimulai dari kebutuhan pelanggan dan berakhir pada persepsi pelanggan Kotler dan Keller (2006). Kualitas layanan dapat dinilai dari lima bagian menurut Sunyoto (2014) antara lain: Tangibles, Reliability, Responsiveness, Assurance, dan Empathy.

$\mathrm{H}_{3}$ : Kualitas layanan berpengaruh terhadap kepuasan konsumen

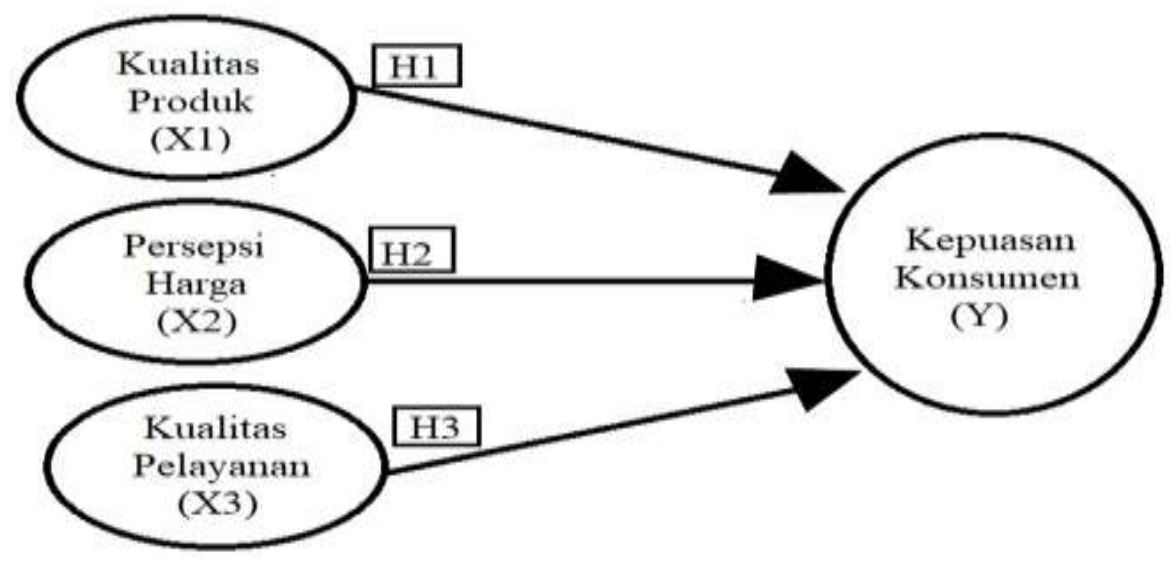

Gambar 1. Kerangka Penelitian

\section{METODA}

Penelitian ini menggunakan variabel bebas dan terikat. Variabel bebas yang digunakan peneliti adalah kualitas produk, persepsi harga, dan kualitas layanan dan variabel terikat yang digunakan adalah kepuasan konsumen. Metode peneliti dalam pengambilan sampel dilakukan secara acak.
Jumlah sampel dalam penelitian ini adalah 100 responden yang pernah membeli kain di Mac Mohan Solo. Pengumpulan data dapat menggunakan instrument penelitian, analisis data bersifat kuantitatif maupun statistik dengan tujuan penulis dapat menguji hipotesis yang telah ditetapkan menurut Sugiyono (2009).

Tabel 1. Skala Likert

\begin{tabular}{lc}
\hline \multicolumn{1}{c}{ Keterangan } & Nilai \\
\hline Sangat Setuju (SS) & 5 \\
Setuju (S) & 4 \\
Netral (N) & 3 \\
Tidak Setuju (TS) & 2 \\
Sangat Tidak Setuju (STS) & 1 \\
\hline
\end{tabular}


Metode pengumpulan data dilakukan dengan cara menyebar kuisioner kepada responden yang sedang, pernah bertransaksi, dan pernah berkunjung ke Toko Tekstil Mac Mohan untuk memperoleh data primer terkait variabel kualitas produk, persepsi harga, kualitas pelayanan, dan kepuasan pelanggan.

Penelitian ini dalam pengukuran variabel menggunakan sistem skor dengan menggunakan skala Likert. Sugiyono (2013) berpendapat skala Likert digunakan sebagai alat mengukur sikap, pendapat, dan persepsi seseorang tentang fenomena sosial.

\section{HASIL PENELITIAN DAN PEMBAHASAN}

Hasil sampel 100 responden di Toko Tekstil Mac Mohan Solo didominasi oleh perempuan besar persentase $62 \%$ kemudian didominasi oleh pengunjung yang berusia antara 23 hingga 28 tahun sebesar $32 \%$ yang sering membeli produk tekstil, , dengan ratarata pembeli bekerja sebagai karyawan dengan persentase sebesar 36\%. dan dengan $37 \%$ responden dengan pendapatan sebesar Rp2.000.000 hingga Rp3.000.000 perbulan.

\section{Hasil Analisis Regresi Berganda}

Tabel 2. Hasil Analisis Regresi Linier Berganda

\begin{tabular}{ccccccc}
\hline \multirow{2}{*}{ Model } & \multicolumn{2}{c}{ Unstandardized Coefficients } & $\begin{array}{c}\text { Standardized } \\
\text { Coefficients }\end{array}$ & \multirow{2}{*}{ T } & Sig. \\
\cline { 3 - 5 } & & B & Std. Error & Beta & & \\
\hline \multirow{2}{*}{1} & (Constant) & 3.614 & 1.784 & & 2.026 & .046 \\
& Kualitas Produk & .144 & .060 & .254 & 2.380 & .019 \\
& Persepsi Harga & .329 & .097 & .347 & 3.383 & .001 \\
& Kualitas Layanan & .108 & .042 & .232 & 2.565 & .012 \\
\hline
\end{tabular}

Sumber: Data primer yang diolah

Hasil Persamaan Regresi: $Y=3,614+0,144$ $\mathrm{X} 1+0,329 \mathrm{X} 2+0,108 \mathrm{X} 3$

a. Variabel X1 (Kualitas produk) dengan nilai 0,144 berhubungan secara positif dan signifikan dengan variabel $Y$ (Kepuasan Pelanggan) maka hubungan variabel kualitas produk dan kepuasan konsumen berbanding lurus searah.

b. Variabel X2 (Persepsi Harga) dengan nilai 0,329 berhubungan secara positif dan signifikan dengan variabel $Y$ (Kepuasan Pelanggan) maka hubungan variabel persepsi harga dan kepuasan konsumen berbanding lurus searah.

c. Variabel X3 (Kualitas Layanan) dengan nilai 0,108 berhubungan secara positif dan signifikan dengan variabel $Y$ (Kepuasan Pelanggan) maka hubungan variabel kualitas layanan dan kepuasan konsumen berbanding lurus searah.

\section{Hasil Koefisien Determinasi $\left(\boldsymbol{R}^{2}\right)$}

Tabel 3. Hasil Koefisien Determinasi $\left(R^{2}\right)$

\begin{tabular}{cccccc}
\hline & \multicolumn{5}{c}{ Model Summary $^{\mathbf{b}}$} \\
\hline Model & $\mathbf{R}$ & R Square & Adjusted R Square & $\begin{array}{c}\text { Std. Error of } \\
\text { the Estimate }\end{array}$ & Durbin-Watson \\
\hline 1 & $.724^{\mathrm{a}}$ & .525 & .510 & 1.33689 & 2.237 \\
\hline
\end{tabular}

Sumber: Data primer yang diolah

Pada data tabel di atas nilai dari koefisien determinasi $\left(R^{2}\right)$ adalah 0,510 (51\%) yang artinya bahwa variabel bebas (Kualitas Produk, Persepsi Harga, dan Kualitas Layanan) mempengaruhi variabel terikat (Kepuasan Konsumen) sebesar 51\%. Sedangkan sisanya sebesar $49 \%$ dipengaruhi oleh faktor lain diluar model regresi, seperti: lokasi, promosi, dan lain sebagainya. 
Hasil Uji Signifikansi Pengaruh Simultan (Uji F)

Tabel 4. Hasil Uji F

\begin{tabular}{ccccccc}
\hline \multicolumn{7}{c}{ ANOVA $^{\mathbf{a}}$} \\
\hline & Model & Sum of Squares & df & Mean Square & F & Sig. \\
\hline \multirow{2}{*}{1} & Regression & 189.383 & 3 & 63.128 & 35.321 & $.000^{\mathrm{b}}$ \\
& Residual & 171.577 & 96 & 1.787 & & \\
& Total & 360.960 & 99 & & & \\
\hline
\end{tabular}

Sumber: Data primer yang diolah

Peneliti melakukan pengujian ini digunakan untuk membuktikan hipotesisnya bahwa variabel X1 (Kualitas Produk), variabel X2 (Persepsi Harga), dan variabel X3 (Kualitas Layanan) secara simultan berpengaruh secara signifikan terhadap variabel Y (kepuasan konsumen). Hal ini kita ketahui bahwa nilai dari $\mathrm{F}$ hitung adalah 35,321 > sedangkan $\mathrm{F}$ tabel yang diperoleh
2,70 dan kemudian kita bisa juga melihat dari sig $0,000<0,05$ maka dalam hipotesis ketiga ini dikatakan adanya pengaruh yang signifikan terhadap variabel Y (Kepuasan Konsumen) pada Toko Tekstil Mac Mohan Solo.

\section{Hasil Uji Signifikansi Parsial (Uji t)}

Tabel 5. Hasil Uji t

\begin{tabular}{|c|c|c|c|c|c|c|}
\hline & \multirow[t]{2}{*}{ Model } & \multicolumn{2}{|c|}{$\begin{array}{l}\text { Unstandardized } \\
\text { Coefficients }\end{array}$} & $\begin{array}{l}\text { Standardized } \\
\text { Coefficients }\end{array}$ & \multirow[t]{2}{*}{$\mathbf{T}$} & \multirow[t]{2}{*}{ Sig. } \\
\hline & & B & Std. Error & Beta & & \\
\hline \multirow{4}{*}{1} & (Constant) & 3.614 & 1.784 & & 2.026 & .046 \\
\hline & Kualitas Produk & .144 & .060 & .254 & 2.380 & .019 \\
\hline & Persepsi Harga & .329 & .097 & .347 & 3.383 & .001 \\
\hline & Kualitas Layanan & .108 & .042 & .232 & 2.565 & .012 \\
\hline
\end{tabular}

Sumber: Data primer yang diolah

a. Variabel X1 (sig. Kualitas Produk) 0,019 $<$ 0,05 maka H0 ditolak dan Ha diterima, diartikan bahwa kualitas produk secara parsial berpengaruh secara signifikan terhadap kepuasan konsumen.

b. Variabel X2 (sig. Persepsi Harga) 0,001 $<0,05$ maka H0 ditolak dan Ha diterima, diartikan bahwa persepsi harga secara parsial berpengaruh secara signifikan terhadap kepuasan konsumen.

c. Variabel X3 (sig. Kualitas Layanan) $0,012<0,05$ maka H0 ditolak dan Ha diterima, diartikan bahwa kualitas layanan secara parsial berpengaruh secara signifikan terhadap kepuasan konsumen.

\section{KESIMPULAN}

Berdasarkan kajian dan hasil dari penelitian terkait Kualitas Produk, Persepsi Harga, dan Kualitas Layanan mempengaruhi
Kepuasan Konsumen di Toko Tekstil Mac Mohan, Solo maka ditarik kesimpulan seperti berikut:

a. Kualitas produk secara signifikan mempengaruhi Kepuasan Konsumen di Toko Tekstil Mac Mohan, Solo, berarti semakin baik kualitas produk maka semakin meningkat kepuasan konsumen.

b. Persepsi Harga secara signifikan mempengaruhi Kepuasan Konsumen di Toko Tekstil Mac Mohan, Solo, berarti harga sesuai dengan kualitas dan harga terjangkau maka kepuasan konsumen akan meningkat.

c. Kualitas layanan berpengaruh secara signifikan terhadap kepuasan konsumen di Toko Tekstil Mac Mohan, Solo, berarti semakin baik kualitas pelayanannya yang diberikan, semakin tinggi juga kepuasan konsumennya. 


\section{REFERENSI}

Assauri, S. (2014). Manajemen Pemasaran. Jakarta: Raja Grafindo Persada.

Assauri, S. (2015). Manajemen Pemasaran: Dasar, Konsep, dan Strategi. Jakarta: PT Raja Grafindo Persada.

Azwar, S. (2017). Reliabilitas dan validitas. Yogyakarta: Pustaka Pelajar.

Bly, R. W. (1993). Keeping Clients Satisfied: Make your service business more successful and profitable. London: Prentice Hall International, Inc. Chandra, T. F. (2016). Service, Quality, dan Satisfaction. Yogyakarta: Andi Offset..

Daryanto, I. S. (2014). Konsumen dan Pelayanan Prima. Penerbit: Gava Media. Yogyakarta.

Fandy, T. (2015). Service Management. Yogyakarta: Andi Offset..

Fandy, T. (2015). Strategi Pemasaran Edisi 4. Yogyakarta: Andi Offset.

Ghozali, I. (2016). Aplikasi Analisis Multivariete Dengan Program IBM SPSS 23 Edisi 8. Penerbit: Badan Penerbit Universitas Diponegoro. Semarang.

J, S. (2006). Pengukuran Tingkat Kepuasan Pelanggan Edisi 3. Jakarta: Rineka Cipta.

Kemenperin.go.id. (2019). Tumbuh Positif, Industri Masih Kontributor Terbesar Ekonomi Hingga 19 Persen. Penerbit: Kementerian Perindustrian Republik Indonesia. Jakarta Selatan.

Kotler, K. L. (2016). Manajemen Pemasaran Edisi 12 Jilid 1. Jakarta: Penerbit: PT Indeks.

Kotler, P. (2009). Prinsip-prinsip Pemasaran. Jakarta: Erlangga.

Kotler, P. (2009). Turbo Marketing. In L. Ludino, My Life, My Way, My Spirit Turbo Marketing (p. 2). Jakarta: PT. Elek Media Komputindo.

Lewis, R. \&. (1983). The Marketing Aspects of Service Quality. Chicago: American Marketing Association.
Liputan6.com. (2019). 5 Tren Busana yang Tetap Hits di 2020. Jakata: Putu Elmira.

Margono, S. (2005). Metodologi Penelitian Pendidikan : Komponen MKDK. Jakarta: PT Rineka Cipta.

Mowen. (2002). Perilaku Konsumen. Edisi 5 Jilid 2. P Jakarta: Erlangga.

Philip Kotler, A. (2001). Prinsip-prinsip Pemasaran Edisi Kedua Belas. Jakarta: Erlangga

Philip Kotler, G. A. (2016). Prinsip-Prinsip Pemasaran Edisi 13 Jilid 1. Jakarta: Erlangga.

Sugiyono. (2015). Metode Penelitian Kombinasi (Mix Methods). Bandung: Alfabeta.

Sugiyono. (2017). Metode Penelitian Kuantitatif, Kualitatif, dan $R \& D$. Bandung: CV Alfabeta.

Sunyoto, D. (2014). Praktik riset perilaku konsumen. Yogyakarta: Center of Academic Publishing Service.

Tjiptono, F. (2014). Pemasaran Jasa, prinsip, penerapan, dan penelitian. Yogyakarta: Andi Offset.

Tjiptono, F. (2016). Service Quality \& Satisfaction edisi 4. Yogyakarta: Andi Offset. Yogyakarta.

W, Gulo. (2002). Metodologi Penelitian. Jakarta: Gramedia.

Wifky dan Soliha, d. E. (2017). Kualitas Produk, Citra Merek, Persepsi Harga dan Keputusan Pembelian Konsumen Honda Mobilio. Proseding Seminar Nasional Multi Disiplin Ilmu \& Call For Papers UNISBANK, 755-762.

BPS.go.id. (akses 13 Oktober 2020). Sebaran Toko Swalayan Menurut Kelompok Komoditas Utama 2019: https://www.bps.go.id/indicator/173/ 1868/1/sebaran-toko-swalayanmenurut-kelompok-komoditasutama.html

Kontan.co.id. (akses 12 Agustus 2017). Kemenperin: Industri mamin tumbuh 7,19\%. Retrieved from industri.kontan.co.id: https://industri.kon$\tan . c o . i d /$ news/kemenperin-industrimamin-tumbuh-719 